\title{
Errors of Some Sextant Sights with a Bubble, from the Queen Elizabeth 2
}

\author{
Frances W. Wright \\ (Smithsonian Institution, Astrophysical Observatory)
}

As a passenger on the Queen Elizabeth 2 on a westward crossing of the Atlantic in late May 1972, I took sextant sights with my standard marine Plath sextant and also with the 'bubble' attachment for this instrument. Inspired by Francis Rogers' 1 discussion of the development of bubble sextants, my project was to compare the accuracy of the bubble sights with that of the conventional marine sextant sights, which require the horizon.

For comparison, I often alternated series of four or more sights from the bubble with as many, or more, sights dependent on the natural horizon. I used the Sun for the celestial body in these observations during the daytime hours of 22-27 May. From my experience as a passenger on many ocean liners, I know that my marine 'horizon' sights can be trusted to give the usual accuracy of marine-sextant sights; in addition, I had as a check the midnight positions of the Q.E.2 as published in the ship's newspaper, The Daily Telegraph. These should be very accurate since the Q.E.2 has the equipment to use electronic and satellite navigation and claims accuracy of 100 feet from the use of one satellite. Otherwise, I worked quite without help from the bridge, because I did not want to disturb the official navigator immediately after the Spring bomb scare, and also because it is more exciting to work independently. Celestial bodies always give true directions for checking the course at any time, and I had my own charts, Almanac, Sight Reduction Tables, and an accurate watch.

The days of 23 and 24 May were the most difficult for the bubble sights because of the wind and waves and consequent pitching of the ship. One significant fact arose, however : on 24 May a rain shower at meridian passage of the Sun prevented natural-horizon sights altogether, but did not prevent some bubble sights while the Sun could be seen high in the sky.

Scatter, as used here, is the difference between any one sight and that point of the mean smooth line or curve at the same time, the mean curve being plotted by eye through each series of four or more sights. The largest scatter in the bubble sights was one case of $62^{\prime}$. There were two cases of about $50^{\prime}$ scatter, and four between $30^{\prime}$ and $45^{\prime}$. All the rest were less than $30^{\prime}$, and the average of all the sights was $8: 7$ (see Table I). The average of $2: 8$ on the three last days, with fairly good weather and seas, was quite satisfactory. This last value was smaller than I had anticipated. It supports the statement of Dunlap and Shufeldt:2 'The accuracy obtainable with the bubble sextant lies in the range of minutes of arc, rather than in tenths, as is the case with the marine sextant using the natural horizon.'

As a result of my experience in this study, I feel it is advisable for a ship to carry a bubble in addition to the conventional horizon sextant, not as a replacement for the latter but for special occasions. Some navigators are already aware of the convenience of this technique, but others have not thought it possible. I 


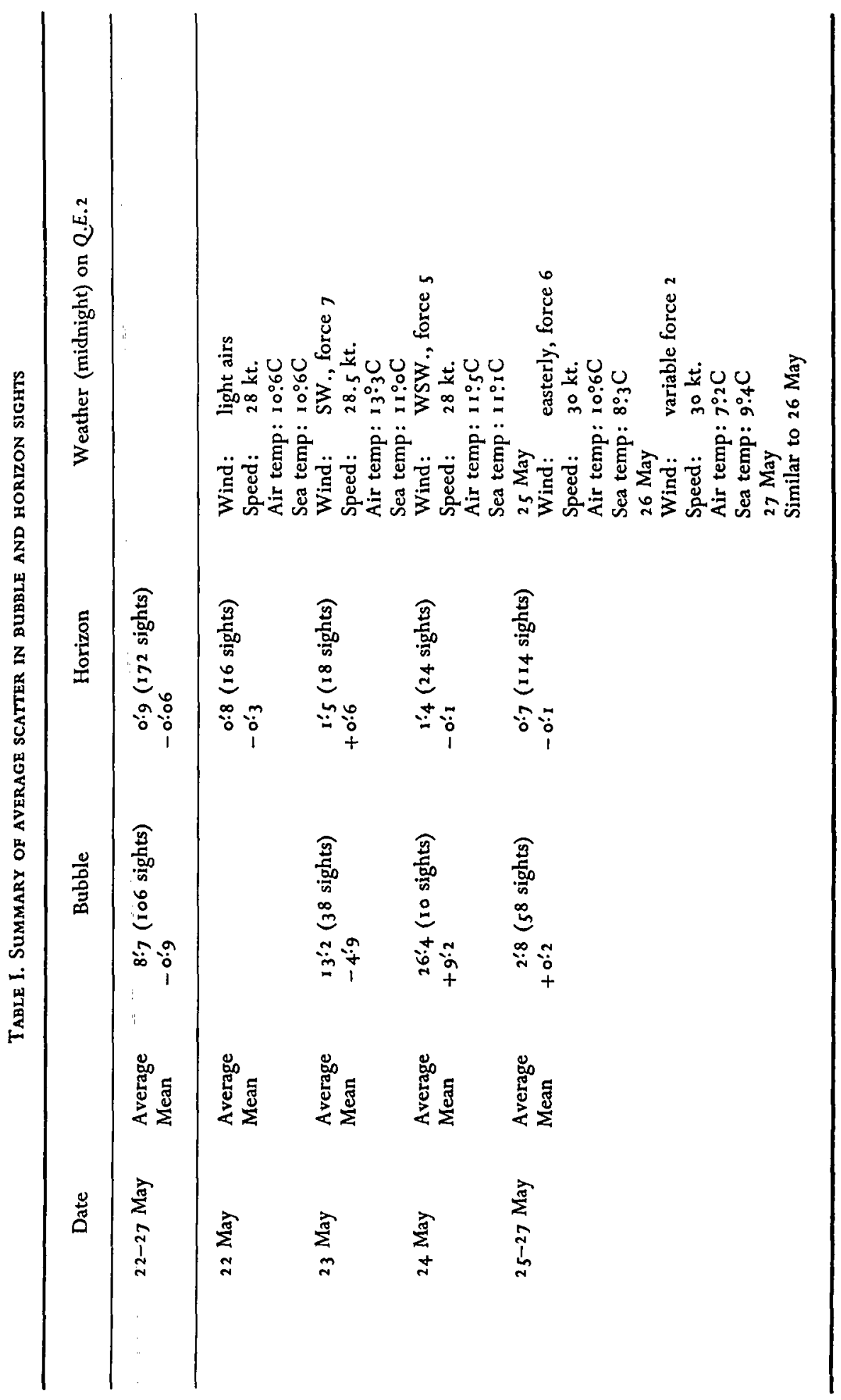


have proved to my satisfaction that the accuracy is most reasonable (at least with the Plath attachment) if four or more sights are taken in a series and a point adopted from the mean line or curve (drawn by eye). I emphasize its use on a ship because more space is available there for additional equipment, and because there is less pitching and rolling. The bubble certainly should be considered as additional equipment and not as a substitute for the natural-horizon marine sextant at sea.

\title{
REFERENCES
}

1 Rogers, Francis M. (1971). Precision Astrolabe, Portuguese Navigators and Transoceanic Aviation, Academia Internacional da Cultura Portuguesa, Lisboa.

2 Dunlap, G. D. and Shufeldt, H. H. (1969). Dutton's Navigation and Piloting. U.S. Naval Institute, Annapolis, Maryland, U.S.A.

\section{The Leap-Second of 31 December 1972}

\author{
D. H. Sadler
}

DetaILs have been given in this Journal (Vol. 25 , pages 32-42) of the new system of Coordinated Universal Time (U.T.C.) introduced on I January 1972. In accord with the agreed recommendations a positive leap-second was introduced at midnight on 30 June 1972 when the value of U.T.I-U.T.C. (DUTI) changed from $-0^{\mathbf{s}} .64$ to +0.36 . However, the Bureau International de l'Heure has now announced that another positive leap-second is to be introduced at midnight on 31 December 1972, when (according to current estimates) U.T. I-U.T.C. will be about -0.2 ; on 1 January 1973 DUT 1 will thus be +0.8 , in excess of the maximum permitted value of $0^{\text {s. }} 7$.

With the introduction of leap-seconds restricted to the last day of any month, with the necessity for a decision at least two months in advance, and with reasonable estimates (based on past records) of the changes in the speed of rotation of the Earth, $0^{s} 70$ is the minimum value that can be assigned to the maximum departure of U.T.C. from U.T.r ; the value of $0^{s} .5$, given in the original draft proposals by C.C.I.R. was misleading. The representatives of the users of U.T. I accepted (albeit reluctantly) the tolerance of $\pm 0^{s} .7$ in order to allow the convenience to other users of U.T.C. of precise one-second jumps at selected, predetermined, times; 0.7 is unduly large for many observations and results in dilution of the observations when corrections for DUTr are either not available or are not applied.

Commission 3 I (Time) of the International Astronomical Union did, however, allow for a possible increase by the statement "The maximum difference U.T.I-U.T.C. will be less than $0^{5} .7$ unless there are exceptional variations in the rotation of the Earth.' This was weakened in C.C.I.R. Report 517 (Journal, page 40 ) to 'The departure of U.T.C. from U.T. r should not normally exceed o.j.'

The present circumstances are normal; the Earth is behaving, and U.T. IU.T.C. is decreasing, in an expected and normal manner. It would have been easy to have kept well within the permitted maximum by deferring the intro- 